\title{
Entraves no mercado da pesca artesanal: entre a dependência e a desconfiança
}

\section{Barriers in the market of small-scale fishing: between the dependency and distrust}

Mauro Macedo Campos - Doutor em Ciência Política pela Universidade Federal de Minas Gerais (UFMG). Professor associado da Universidade Estadual do Norte Fluminense Darcy Ribeiro (UENF). E-mail: mauromcampos@uenf.br

Lohana Chagas de Almeida - Mestra em Sociologia Política pela Universidade Estadual do Norte Fluminense Darcy Ribeiro (UENF).E-mail: lohanachadeal@hotmail.com

Geraldo Márcio Timóteo - Doutor em Sociologia pela Universidade Federal de Minas Gerais (UFMG). Professor associado da Universidade Estadual do Norte Fluminense Darcy Ribeiro (UENF). E-mail: geraldotimoteo@gmail.com

\section{Resumo}

Este artigo analisa os mercados acessados pelos pescadores artesanais das comunidades pesqueiras de Campos dos Goytacazes, região Norte do estado do Rio de Janeiro. As informações para a elaboração deste estudo foram coletadas em reuniões com os pescadores, em grupos focais e por meio de questionários aplicados de forma censitária. O levantamento dos mercados efetivos e potenciais buscou identificar as possibilidades de escoamento de pescado no município e os entraves burocráticos que limitam a constituição de novos mercados. Os resultados evidenciaram um número elevado de vendedores (os pescadores artesanais) em contraponto ao reduzido número de compradores (os atravessadores) de uma produção altamente perecível, que domina o mercado da pesca artesanal no município. A produção tem origem dispersa, em um contexto de baixa organização social e falta de confiança entre os pescadores, o que dificulta ações conjuntas em busca de novos canais de comercialização da pesca artesanal.

\section{Palavras-chave}

Mercado da Pesca Artesanal. Dependência dos Atravessadores. Organização Social. Falta de Confiança.

\begin{abstract}
This article analyzes the markets accessed by artisanal fishermen from the fishing communities of Campos dos Goytacazes, in the northern region of the state of Rio de Janeiro. The information for the preparation of this study was collected in meetings with artisanal fishing, in focus groups and through questionnaires applied in a census form. The survey of the effective and potential markets sought to identify the possibilities of fish outlets in the local and the bureaucratic obstacles that limit the constitution of new markets. The results showed a high number of sellers (artisanal fishermen) as opposed to the small number of brokers (middlemen) of highly perishable production, who dominate the artisanal fishing market in the local. The production has a dispersed origin, in a context of low social organization and lack of trust among fishermen, which makes joint actions in search of new channels of commercialization of artisanal fisheries difficult.
\end{abstract}

\section{Keywords}

Artisanal Fisheries Market. Dependence on Middleman. Social Organization. Lack of Confidence. 


\section{INTRODUÇÃO ${ }^{1}$}

Este artigo analisa dois pontos essenciais no mercado da pesca artesanal. O primeiro diz respeito ao acesso aos canais de comercialização pelos pescadores artesanais. O segundo problema, intimamente vinculado ao primeiro, é a fragilidade da organização produtiva e social da classe pesqueira (DIEGUES, 1999; DUARTE, 1999). Essas questões compõem a base argumentativa deste estudo, que foi realizado com os pescadores artesanais de Campos dos Goytacazes, Norte do estado do Rio de Janeiro, entre os anos de 2014 e 2016.

A pesca artesanal representa um segmento importante sobretudo nas regiões costeiras. A força de trabalho que move esse setor é composta, na maioria das vezes, por famílias de pescadores que se ocupam da captura do pescado sozinhos, ou com o auxílio de camaradas, cuja atividade, na produção, é dividida em partes, que variam a partir de acordos prévios estabelecidos antes da realização da captura do pescado, considerando as atividades exercidas por cada um dos pescadores (CLAY; OLSON, 2008; DIEGUES, 1999). De modo geral, são atividades que partem de um processo de gerenciamento e de controle de base tradicional, mas com conhecimento prático e com capacidade para lidar com a complexidade do ecossistema e com a dinâmica social e econômica que forma a pesca artesanal (ANDREW; EVANS, 2009).

O locus da pesquisa está localizado na área litorânea do estado do Rio de Janeiro, conhecida como Bacia de Campos (BC), que concentra grande parte dos investimentos no setor de petróleo e gás e da produção offshore. A Bacia de Campos possui 55 campos de petróleo com 826 poços exploratórios. Inserido nesse espaço, o município de Campos dos Goytacazes tem a sua importância econômica impulsionada pela chamada sorte geográfica (SERRA; PATRÃO, 2003), que o torna um dos grandes receptores dos recursos dos royalties e participações especiais, refletindo no seu volume orçamentário. Nesse ambiente competitivo, a Petrobras - principal empresa do setor no Brasil - atua em conformidade com outros gigantes do setor de petróleo e gás. É um cenário onde essas corporações lidam cotidianamente com as comunidades pesqueiras, sobretudo por meio dos projetos de mitigação e de compensação ambiental, exigidos pelo Instituto Brasileiro do Meio Ambiente e dos Recursos Naturais Renováveis (Ibama) (CAMPOS; TIMÓTEO; ARRUDA, 2018).

1 Este artigo é resultado de pesquisa financiada pelo Projeto de Educação Ambiental (PEA)-Pescarte que é uma medida de mitigação exigida pelo Licenciamento Ambiental Federal, conduzido pelo Ibama. 
Ao adentrar o universo dos pescadores artesanais, observam-se problemas de diferentes ordens que, muitas vezes, passam pela desorganização de seu processo produtivo, apresentando deficiências que vão desde a obtenção de insumos (gelo, óleo diesel, apetrechos de pesca, entre outros) até a comercialização de seus pescados. Normalmente o resultado da produção pesqueira, em cada saída de pesca ou "primeira venda", é entregue aos chamados "atravessadores", que atuam nessa cadeia produtiva, como agentes de comercialização. Vale ressaltar que essa chamada "primeira venda" ocorre até mesmo antes do embarque do pescador, como um acordo com o atravessador, via acordo de custeio dos insumos para a saída do barco.

Trata-se de uma prática recorrente entre as partes e que persiste não apenas por condições financeiras, mas envolve ainda questões sociais e simbólicas (DIAS NETO, 2012; DIEGUES, 1999). São os atravessadores que estabelecem o contato com a rede de compradores. Eles, quase sempre, pagam aos pescadores preços que têm, como parâmetro, um mercado que varia no sentido contrário em relação ao sucesso obtido na pescaria, ou seja, quanto maior for a quantidade de pescado capturada, menos eles recebem por quilograma do produto. Vale ressaltar que a venda é quase obrigatória, pois os pescadores não podem manter o pescado em estoque por muito tempo (dada a perecibilidade), à espera de melhores preços, e ainda há a falta de acesso a outros canais de comercialização (PEARSON et al., 2011).

Nesse sentido, o artigo traz, como uma inovação, a busca por identificar os canais de comercialização do pescado acessados pelos pescadores artesanais, sobretudo na "primeira venda". E, desse modo, alinhados aos estudos mais recentes da Comissão Econômica das Nações Unidas para a América Latina (CEPAL, 2014), em que se ressaltam os ganhos (para produtores, consumidores e poder público local) das cadeias curtas de comercialização. Com efeito, a partir da lógica das cadeias curtas, o estudo desenvolve uma espécie de "inventário" de possibilidades de canais de comercialização, acessíveis aos pescadores do município.

\section{METODOLOGIA}

O estudo tem, como base, uma pesquisa descritiva, com uma abordagem qualitativa, embora contemple elementos quantitativos, a partir dos dados de 
campo obtidos pelo Projeto de Educação Ambiental do Licenciamento Federal de Petróleo e Gás (PEA) Pescarte ${ }^{2}$. Os sujeitos da pesquisa foram os pescadores artesanais e suas famílias, das dez comunidades pesqueiras ${ }^{3}$ (marítimas e continentais) de Campos dos Goytacazes, perfazendo 1.643 pessoas distribuídas em 586 famílias.

Para o desenvolvimento deste estudo, foram considerados: (1) os relatos dos pescadores artesanais e familiares captados nas reuniões e em quatro grupos focais: dois grupos, um de homens e outro de mulheres; um grupo formado por jovens, filhos e filhas de pescadores; e um quarto grupo misto, com homens, mulheres e jovens. Ao todo, foram 34 participantes. Um dos objetivos dos grupos focais era identificar os mercados acessados pelos pescadores, as suas relações com os atravessadores e quais os principais problemas na comercialização; (2) aliado aos grupos focais, foi realizado um questionário estruturado, aplicado censitariamente à comunidades de pesca, com alcance de 4.331 pescadores nos municípios do projeto; e (3) consultas diretas a órgãos públicos e em sites institucionais para realizar o levantamento dos mercados potenciais (públicos e privados).

A iniciativa de aplicar um censo não é algo trivial, tendo em conta a existência de um alto grau de desconfiança histórica dos pescadores em relação ao processo de exploração do petróleo e gás, na costa brasileira (DIEGUES, 1999; DUARTE, 1999). Obter a "confiança" dos pescadores artesanais foi uma condição essencial para realizar a entrada da equipe de pesquisa no campo, afinal eles não relatavam as suas realidades sociais. Estabelecer esse rapport junto às comunidades pesqueiras demandou tempo, porém foi capaz de reduzir a tensão e a desconfiança existentes entre os pescadores e a equipe de pesquisa.

Os questionários foram aplicados nos sete municípios, alcançando 3.478 famílias em que foram entrevistados 4.748 pescadores. No município de Campos dos Goytacazes, foram entrevistadas 586 famílias, perfazendo 821 pescadores, com informações sobre 1.643 pessoas. Os respondentes principais foram os indivíduos ligados diretamente à cadeia da pesca e, quando o recenseador era informado da existência de algum outro pescador na família, esse também era entrevistado. Para este estudo, não foram consideradas as pessoas que não exerciam atividades relacionadas à pesca, como também, não foram entrevistados os atravessadores, comerciantes e donos de embarcações que apenas alugam os barcos.

2 O projeto PEA-Pescarte atua Bacia de Campos (BC) em sete municípios: Arraial do Cabo, Cabo Frio, Macaé, Quissamã, Campos dos Goytacazes, São João da Barra e São Francisco do Itabapoana.

3 Comunidades em Campos dos Goytacazes: Farol de São Tomé, Terminal Pesqueiro, Coroa Grande, Lagoa de Cima, Parque Prazeres, Ponta Grossa dos Fidalgos, Sant’ana, Lagoa de Cima, Lagoa do Vigário e Tocos. 
A pesquisa censitária teve, como unidade, os domicílios dos pescadores e de suas famílias, sendo composta por dez blocos de perguntas divididos em (1) Identificação socioeconômica e características demográficas; (2) Caracterização familiar; (3) Avaliação de serviços públicos (Habitação, Energia, Água, Esgoto); (4) Avaliação de serviços e equipamentos públicos (Saúde, Educação, Assistência Social, Cultura, Comunicação); (5) Trabalho e trajetória profissional; (6) Caracterização da atividade pesqueira; (7) Capital social e laços fracos; (8) Gênero; (9) Módulo de caracterização da Educação Ambiental na Bacia de Campos; e (10) Inquérito alimentar para pescadores. Para a elaboração deste artigo, foram utilizados os Blocos 5 e 7.

Buscou-se ainda mapear os potenciais canais de comercialização do setor privado. Esse trabalho foi feito junto à Secretaria Municipal de Fazenda de Campos dos Goytacazes, onde foram identificados os pontos de consumo e de revenda, como bares e restaurantes, hortifrutigranjeiros, hipermercados e mercados, cadastrados nesse órgão.

A coleta dos mercados potenciais públicos foi efetuada por meio de consultas aos órgãos públicos, em sites institucionais e contatos com agentes públicos. Os mercados foram evidenciados por meio das compras governamentais ${ }^{4}$. Vale ressaltar que esses mercados indicam possibilidades (não mais que isso) para o escoamento da produção realizada pelos pescadores. Nessas duas modalidades, o esforço ocorreu na direção de identificar redes curtas de comercialização (CUNHA, 2018) em que se pudesse vincular as comunidades pesqueiras.

\section{CARACTERIZAÇÃO DA ATIVIDADE PESQUEIRA NO BRASIL}

A pesca é definida, de acordo com o Artigo $2^{\circ}$ da Lei no $11.959 / 2009$, como "[...] toda a operação, ação ou ato tendente a extrair, colher, apanhar, apreender ou capturar recursos pesqueiros" (BRASIL, 2009). É uma das atividades mais tradicionais do Brasil, baseada na captura de peixes, de crustáceos e de moluscos. Esse ofício é realizado por trabalhadores que vivem nas comunidades pesqueiras, que são espaços reconhecidos por sua importância econômica e social, com uma forte carga de tradições e valores (DIEGUES, 1995).

A atividade da pesca, segundo o Artigo $8^{\circ}$ da legislação de 2009, é classificada de dois modos distintos: comercial e não comercial. A pesca não comercial não almeja fins lucrativos e comerciais, estando dividida em: científica

4 O conceito de compras governamentais, segundo Ribeiro e Inácio Júnior (2019), relaciona-se às compras de bens e de serviços realizados pelos governos, incluindo fornecedores nas esferas dos serviços públicos. 
(exercida com o objetivo de pesquisa); amadora (praticada almejando o lazer ou o desporto); e de subsistência (visa ao consumo doméstico ou escambo). A pesca comercial está voltada para fins lucrativos, estando dividida em pesca artesanal e industrial. Tem-se, dessa forma:

a) Artesanal: quando praticada diretamente por pescador profissional, de forma autônoma ou em regime de economia familiar, com meios de produção próprios ou mediante contrato de parceria, desembarcado, podendo utilizar embarcações de pequeno porte;

b) Industrial: quando praticada por pessoa física ou jurídica e envolver pescadores profissionais, empregados ou em regime de parceria por cotaspartes, utilizando embarcações de pequeno, médio ou grande porte, com finalidade comercial (BRASIL, 2009).

\subsection{PESCA INDUSTRIAL}

Durante as primeiras décadas do século XX, a atividade pesqueira ganhou escala no Brasil, iniciando pela captura da sardinha, com o uso de trainas (grandes redes). As primeiras traineiras surgiram na Ilha Grande, RJ. Na esteira da sobrepesca, originaram-se as primeiras indústrias de salga e secagem no Rio de Janeiro, RJ, e em Santos, SP. Porém, no país, a primeira indústria pesqueira com base empresarial foi implantada na década de 1960, com incentivos da Superintendência do Desenvolvimento da Pesca (Sudepe). A maior parte dessas empresas foi criada no litoral centro-sul do Brasil, utilizando trawlers $^{5}$ na coleta de camarão para a exportação (DIEGUES, 1995).

A pesca industrial representa um segmento relevante para a economia, principalmente, para os municípios litorâneos, sendo uma importante fornecedora de matéria-prima para indústrias de alimentos (SANTOS JÚNIOR, 2014). Geralmente, para a realização dessa modalidade de pesca, caracterizada pela alta tecnologia, utiliza-se do Sound Navigation and Ranging (Sonar), que funciona como um radar com capacidade para localização de cardumes, o que auxilia no sucesso das capturas. Já na pesca artesanal, o uso de tecnologia resume-se, sobretudo, ao emprego do sistema de localização via satélite, o Global Positioning System (GPS). Além disso, a pesca industrial distingue-se pelo tipo de embarcação (acima de 20 toneladas de arqueação bruta) e pela relação de trabalho na qual os pescadores possuem vínculo empregatício (BEGOT; VIANNA, 2014).

O trawler (rebocador, barco de arrasto) é uma embarcação com casco semideslocante mais veloz e instável. 


\subsection{PESCA ARTESANAL}

A pesca artesanal abrange um grupo social que convive em um ambiente de estruturas relacionais complexas, onde a compreensão do termo organização social ganha contornos variados e que podem ser utilizados de diferentes maneiras, relacionando-se às questões organizacionais, instituições e grupos (WALDER, 1978), com regras de conduta social. Como apontado por autores como Duarte (1999) e Barbosa (2004), o espaço da pesca é o mesmo lugar onde vivem. Entre esses pescadores, não é incomum confeccionarem suas artes e instrumentos de pesca. Utilizam pequenas embarcações como barcos, jangadas e canoas, construídas por estaleiros, e a atividade é relevante na economia local (BEGOT; VIANNA, 2014; DIEGUES, 1999), como é o caso do Norte do Rio de Janeiro.

O processo de trabalho, na pesca artesanal, não apresenta muita afinidade com a pesca industrial. A principal diferença está nas técnicas, nos equipamentos adotados, no tipo de embarcação e na quantidade de pescado obtido (RODRIGUES; GIUDICE, 2011). Santos Júnior (2014), indo de encontro aos argumentos de Diegues (1995), define o pescador artesanal como aquele que exerce a atividade de maneira autônoma ou em regime de economia familiar com mecanismos próprios ou por meio de parcerias, sendo que a maioria das famílias de pescadores retira dessa atividade sua principal fonte de renda, contudo esse aspecto convive com a realidade de que muitos pescadores já passaram a exercer outras atividades para complementarem a renda, isso devido à inconstância e à insuficiência da renda originária da pesca, compondo o fenômeno denominado de pluriatividade (CLAUZET; RAMIRES; BARRELLA, 2005; DUARTE, 1999; SACCO DOS ANJOS; NIEDERLE; CALDAS, 2004).

A pesca artesanal comercial é caracterizada pela combinação da captura de espécies de pescado em águas mais rasas e com baixa autonomia para as embarcações. Refere-se a um tipo de pesca destinada ao consumo próprio e à venda em pequena escala (ANDREW; EVANS, 2009; LEVKOE; LOWITT; NELSON, 2017). As artes de pesca comportam um intrincado conjunto de aprendizados que a um observador pouco familiarizado com esse trabalho se apresenta como sendo algo simples, mas seu uso é orientado pelos saberes tradicionais que, na maioria das vezes, é repassado pelos pescadores mais velhos, os mestres de pescaria, aos mais novos e que se materializam, por exemplo, em situações de quando e onde usar esses petrechos em situações adversas de tempo, vento, correnteza das águas, e principalmente esses mestres conhecem a localização dos pesqueiros, que, em razão de sua importância, são mantidos em segredo (DIEGUES, 1995; RAMALHO, 2012). 
Em virtude das características que demarcam a conexão da pesca artesanal com os recursos naturais no ambiente de pesca, evidencia-se a importância socioambiental que esse setor representa (CLAY; OLSON, 2008; RODRIGUES; GIUDICE, 2011). Possui um menor impacto ecológico em comparação com a pesca industrial (PEARSON et al., 2011), que ocorre, na maioria das vezes, em mar aberto.

Nesse ambiente de pesca marítima, a pesca artesanal, quase sempre, é praticada perto da costa, mas não é rara a presença de embarcações pesqueiras que realizam a captura de pescado perto das plataformas de petróleo. Para tanto, essas embarcações navegam por uma distância superior a 300 quilômetros da costa. Em alguns casos, os pescadores arriscam-se ainda mais, em busca do pescado, ficando a menos de 500 metros das plataformas, consideradas áreas de segurança industrial (CLAUZET; RAMIRES; BARRELLA, 2005).

\section{RESULTADOS E DISCUSSÕES: PESCADORES DE CAMPOS DOS GOYTACAZES}

Ao longo da pesquisa, foram ouvidos pescadores e seus familiares em reuniões e grupos focais realizados nas comunidades pesqueiras em Campos dos Goytacazes, onde coexistem duas modalidades de pescadores: os marítimos e os de águas continentais. Há também uma diferença em relação ao estoque pesqueiro, com uma quantidade satisfatória na costa, em contraponto com a escassez do pescado nas águas de interiores e com um acentuado processo de degradação dos corpos aquáticos (CAMPOS; TIMÓTEO, 2017).

De acordo com a fala de um representante da pesca local, isso ocorre em função da "[...] ausência da fiscalização quanto às redes utilizadas para a pesca e que não respeitam o período do seguro defeso". Esse benefício - semelhante ao seguro-desemprego, porém restrito ao pescador artesanal - é uma política pública, regulamentada pela Lei no 10.779 de 2003, que mantém a renda dos pescadores, além de estabelecer um período de suspensão da pesca (variado por espécie), visando garantir o período de desova e o crescimento da espécie. $\mathrm{Na}$ fala, o pescador destaca (informações verbais) ${ }^{6}$ : "[...] a falta de consciência dos próprios pescadores", que, em sua opinião, representa um dos principais motivos dessa escassez de peixes nas lagoas do município. O pescador de Lagoa de Cima acrescenta: "precisa de fiscalização".

\footnotetext{
6 Informações verbais fornecidas por Zé Hugo, pescador da comunidade Lagoa de Cima, em Campos dos Goytacazes, no dia 10 de março de 2015.
} 


\subsection{AS REUNIÕES E OS GRUPOS FOCAIS DO PROJETO PEA-PESCARTE}

As falas dos participantes apontavam incredulidade e desconfiança em relação aos projetos de educação e mitigação ambiental, ressaltando um dos sujeitos da pesquisa: “[...] sou pescador há 19 anos e já estou cansado de escutar promessas de projetos anteriores e nada ter sido feito. Não vejo benefício para o pescador [...] ter conhecido projetos que tinham muito dinheiro e eles não viram nada”. Nessa mesma direção, um dos líderes da comunidade pesqueira de Farol de São Thomé disse: "[...] a Petrobras nunca trouxe proposta concreta; só existem propostas no papel". Esse ponto de desgaste foi percebido tanto nas reuniões, como nos grupos focais, e as "tensões" eram voltadas para a empresa Petrobras. Nas palavras do pescador: “[...] estão com o pé atrás e que ninguém mais acredita nessas promessas: a Petrobras só faz teatro e não dá nada para resolver o problema dos pescadores. Só precisa de foto para provar que teve participação" (informações verbais) ${ }^{7}$. São falas que se assemelham ao estudo de Barbosa (2004) realizado com pescadores da Colônia Z-7, em Itaipu, Niterói, Rio de Janeiro.

Foi apontado ainda, por uma liderança dos pescadores da comunidade Farol de São Thomé, que "[...] as plataformas tiram todos os espaços da pesca com a sísmica". Esse é um ponto recorrente na fala dos pescadores artesanais, que ressaltam a interferência da indústria de petróleo e gás. "Os navios espantam os peixes; dão um choque na água, podendo ser sentido no barco, mesmo a grandes distâncias" (informações verbais)', o que dificulta a pesca.

Ditty e Rezende (2013) trazem um estudo sobre a percepção dos pescadores artesanais sobre os impactos causados pela indústria de petróleo e gás nessa mesma comunidade, onde, segundo os autores, ocorreram:

$[\ldots]$ modifications of the patterns of marine currents; alteration or loss of the superficial soil layer; reductions in local fauna and flora; the appearance of invasive biological organisms; the exclusion of other economic uses in the region; alterations in the natural characteristics of the air, sea, rivers, and other environments (DIT'TY; REZENDE, 2013, p. 54).

No entanto, vale ressaltar que não é apenas a atividade de petróleo e gás que interfere na pesca artesanal. A região é também marcada pela presença

\footnotetext{
Informações verbais fornecidas por Rodolfo, presidente da Colônia Z-19, na comunidade de Farol de São Thomé, em Campos dos Goytacazes, no dia 08 de novembro de 2014.

8 O evento da sísmica é uma atividade que consiste no uso de equipamentos para identificar a presença de minerais no subsolo marinho.

9 Informações verbais fornecidas por Marcelo, pescador da comunidade de Farol de São Thomé, em Campos dos Goytacazes, no dia 08 de novembro de 2014.
} 
ativa da pesca industrial em larga escala e com equipamentos de alta tecnologia, principalmente, na pesca do camarão, uma vez que é grande produtora desse tipo de pescado (ZAPPES; OLIVEIRA; DI BENEDITTO, 2016). Segundo relatos dos pescadores artesanais no grupo focal, "[...] a pesca industrial 'pega' os maiores peixes, deixando apenas os pequenos" (informação verbal) ${ }^{10}$. Além desses problemas destacados nas falas dos pescadores e que impactam a atividade da pesca, há outras questões, como o preço elevado do combustível para o funcionamento dos barcos de pesca. Um pescador foi enfático ao dizer que "[...] o problema do mar é o diesel, que representa mais de $90 \%$ do custo do pescador. Não vale a pena mais entrar na água" (informação verbal) ${ }^{11}$.

A fala de outro pescador no grupo: “[...] somos produtores, a classe mais sofrida, e os atravessadores é que ganham. Se o governo olhasse para isso, os pescadores estariam em situação melhor de vida" (informação verbal) ${ }^{12}$. Apesar da "confusão" sobre o papel do setor público, ainda assim, esse é um argumento central neste artigo. Afinal, se se pretende avançar no entendimento sobre o funcionamento do mercado da pesca artesanal, compreender em quais situações ocorre a chamada "primeira venda" é essencial para que se possa discutir a questão da dependência dos pescadores artesanais em relação aos atravessadores. Foi dito que "[...] a maior dificuldade está no monopólio da compra do produto pelo atravessador". Isso reflete na baixa autonomia para a busca de novos mercados, o que contribui para que os pescadores sejam inseridos nesse mercado, de maneira subordinada (BARBOSA, 2004; DIEGUES, 1999; DUARTE, 1999). Em outras palavras, “[...] o problema do peixe é o preço, sendo sempre um terceiro a ditar o preço (informações verbais) ${ }^{13 "}$. No entanto, esse sentimento não muda o fato de enxergarem, no atravessador, uma estrutura de suporte.

Porém, o que foi dito pelo pescador como sendo um "monopólio da compra" por parte do atravessador, na realidade, é um tipo de mercado mais complexo, com uma estrutura de oligopsônio - onde existe uma concentração em poucos compradores (que, segundo eles, são os atravessadores) e muitos vendedores (que são os pescadores artesanais), por referir-se a um mercado com traços de informalidade cuja operacionalização ocorre em um ambiente no qual o poder público pouco alcança (MOITA; GOLON, 2014).

10 Informação verbal fornecida por Vinicius, pescador da comunidade de Farol de São Thomé, em Campos dos Goytacazes, no dia 08 de novembro de 2014.

11 Informação verbal fornecida por Zezildo, pescador da comunidade de Farol de São Thomé, em Campos dos Goytacazes, no dia 10 de março de 2015.

12 Informação verbal fornecida por Zé do Brejo, pescador da comunidade de Tocos, em Campos dos Goytacazes, no dia 24 de abril de 2015.

13 Informações verbais fornecidas por Marli, pescadora da comunidade de Farol de São Thomé / Gaivota, em Campos dos Goytacazes, no dia 09 de março de 2015. 
Essa relação é ainda mais complexa, pois não se restringe apenas ao aspecto mercantil da "primeira venda" do pescado. Ela vai além, pois, na teia que envolve o pescador artesanal e o atravessador, há outras formas de reforçar a fidelidade da venda do pescado (COSTA, 2019; MALDONADO, 1994), que vão da garantia da compra do pescado, passando pelo financiamento da saída para a pesca (isso envolve a compra do rancho, das iscas, dos petrechos de pesca, do gelo para o armazenamento do pescado e do combustível para o barco). Dessa forma, o pescador vê-se obrigado, muitas vezes, a comprar tudo do próprio atravessador, embora seja muito mais caro do que em outros locais, mas, se não compra do atravessador, esse não adquire seu pescado. Adiciona-se a esse quadro uma série de desembaraços pessoais, de "pequenos débitos" com os atravessadores (CAPELLESSO; CAZELLA, 2013). É uma relação com uma elevada assimetria informacional, em que permanecem os aspectos pouco transparentes para os pescadores, no que diz respeito aos valores oferecidos para o consumidor final, sustentada na aversão ao risco e nos baixos custos de transação.

Um dos participantes dos grupos focais foi enfático ao dizer: “[...] os pescadores vivem sob os pés dos atravessadores, pois não têm concorrência e nem voz ativa" e que: “[...] estou parando de pescar porque já não vejo mais futuro na área da pesca”. Ele ainda ressaltou: “[...] no mar, quem dá o valor do pescado é o atravessador". Mas, “[...] quando o comprador é 'de fora' o preço do pescado é melhor". Nesse último relato, o pescador fez referência à venda que é realizada sem a participação do atravessador. O pescador continua dizendo: “[...] nunca vai se ver pescador rico, mas os atravessadores são." (informações verbais ${ }^{14}$. Tais questões foram observadas também pelos autores Capellesso e Cazella (2013) quando analisaram o cotidiano dos pescadores do litoral centrosul catarinense e a relação com os atravessadores.

Acontece que sair da "dependência do atravessador" não é algo simples, como aponta parte da literatura especializada, afinal "[...] pescador é pescador e feirante é feirante" (informação verbal) ${ }^{15}$, como ressaltou um pescador em grupo focal. Isso faz toda a diferença.

Além das questões práticas do cotidiano da pesca, como o financiamento para a própria saída para o barco, que envolve uma série de custos (mencionados anteriormente), há também o fato de que, ao desembarcarem com o pescado, não há uma estrutura apropriada para os pescadores efetuarem a "primeira venda" de forma planejada e mais justa. Além disso, os pescadores também não têm

14 Informações verbais fornecidas por Sr. Ninil, pescador da comunidade de Coroa Grande, em Campos dos Goytacazes, no dia 08 de maio de 2015.

15 Informação verbal fornecida por Zélia Parruda, pescadora da comunidade de Coroa Grande, em Campos dos Goytacazes, no dia 08 de maio de 2015. 
"disposição para essa venda do pescado", a não ser para aqueles de costume (os atravessadores), que os aguardam nos pontos de desembarque, ou os pescadores, antes mesmo da saída de pesca, já estabelecem um acordo prévio para a compra do pescado. É uma relação forte, apesar de informal, que pode significar um elemento de proteção ao pescador em razão da inexistência de um apoio público à atividade desenvolvida. O conflito é uma questão inerente em qualquer situação em que a coalizão entre os atores envolvidos requer alguma disputa ou barganha (CHOUERI; NASCIMENTO, 2019). Em tais circunstâncias, evidenciamse situações de cooperação e de punição muito evidentes nas relações entre pescadores artesanais e atravessadores (MOITA; GOLON, 2014).

O enredo é ainda mais intrincado no momento em que a questão recai no processo das vendas institucionais. Para esse tipo de comercialização, há um conjunto de exigências de controle sanitário, nos três níveis da federação, para um produto altamente perecível. Abrangem o Serviço de Inspeção Municipal (SIM), o Serviço de Inspeção Estadual (SIE) e o Serviço de Inspeção Federal (SIF), que são selos de inspeção de produtos de origem animal.

Tais procedimentos controlam o que é comercializado. Segundo informações da Secretaria Municipal de Agricultura, "[...] nenhum pescador possuía registro no SIM na prefeitura de Campos" (informação verbal) ${ }^{16}$. Nessa mesma direção, um pescador reforçou: “[...] é difícil entrar nesse mercado [público], é complicado chegar a preços justos, pois, se fosse de outra forma, nós não entregaríamos nossos pescados aos atravessadores [...].” (informação verbal $)^{17}$. Ainda reforçou o fato de que seria bom que "[...] elaborassem um selo de qualidade". Sobre esse aspecto, Spers (2003) considera que esses selos podem mudar o comportamento de um nicho de consumidores que buscam produtos socialmente justos e ambientalmente sustentáveis (FAO, 2016; WILLOUGHBY; GORE, 2018), com ganhos incrementais da cultura local e da organização social.

Ao abordar esse aspecto nos grupos focais, as soluções em conjunto foram destacadas como sendo o caminho para conseguirem melhorar suas condições de trabalho e de renda. A formalização de uma cooperativa ou associação que pudesse agregar valor ao pescado, seja pela venda conjunta, ou por meio do beneficiamento, foi um apontamento em todos os grupos focais e reuniões de campo. Essa mesma abordagem foi sugerida pelo servidor da Secretaria de

16 Informação verbal fornecida por Gédison, médico veterinário do Serviço de Inspeção Animal da Secretaria Municipal de Agricultura, do município de Campos dos Goytacazes, no dia 20 de janeiro de 2016.

17 Informação verbal fornecida por Zé do Brejo, pescador da comunidade de Tocos, em Campos dos Goytacazes, no dia 24 de abril de 2015. 
Agricultura ao ressaltar que: "[...] seria mais proveitoso para todos os pescadores estabelecer as organizações por meio de uma cooperativa ou associação para solicitarem as suas entradas no Serviço de Inspeção Municipal de Campos (SIM/ CG)" (informação verbal) ${ }^{18}$.

Apesar da fala recorrente de que as ações conjuntas propiciam soluções para os problemas da comercialização do pescado, o que se observou foi um paradoxo, pois, tanto nas reuniões com as comunidades, como nos grupos focais, observou-se uma resistência quanto a esse tipo de empreendimento, afinal lidam com a confiança e com as expectativas das pessoas e partem de um campo de trabalho solidário, no qual a renda assume um caráter premente (VERONESE; GUARESCHI, 2005). Ao serem questionados sobre iniciativas cooperadas, disseram que projetos com esse perfil já foram implantados, porém "não deram certo". Ao serem perguntados sobre a possibilidade de uma união entre os pescadores, há uma concordância de que “[...] seria difícil pelo descaso de seus companheiros [...] o pescador vive cada um por si, não conversam entre si”. A fala foi logo completada por outro pescador, ao dizer que "[...] não adianta cooperativa se não tiver peixe ou união entre os pescadores." (informações verbais) ${ }^{19}$.

A questão da confiança foi trabalhada no Censo PEA-Pescarte, no Bloco: Capital Social e Laços Fracos. O resultado é retratado na Tabela 1, que aponta o problema da confiança entre os pescadores, onde quase $70 \%$ dos entrevistados não indicariam ninguém de confiança na comunidade.

Tabela 1 - A pessoa que você mais confia na comunidade

\begin{tabular}{c|c}
\hline Relação de confiança & Pescadores artesanais de Campos dos Goytacazes \\
\hline Não indicaram ninguém & $68,60 \%$ \\
\hline Indicaram 1 pessoa & $15,00 \%$ \\
\hline Indicaram 2 pessoas & $10,60 \%$ \\
\hline Indicaram 3 pessoas & $4,90 \%$ \\
\hline Indicaram 4 pessoas & $0,50 \%$ \\
\hline Indicaram 5 pessoas & $0,30 \%$ \\
\hline
\end{tabular}

Fonte: Censo PEA-Pescarte (2015)

18 Informação verbal fornecida por Gédison, médico veterinário do Serviço de Inspeção Animal da Secretaria Municipal de Agricultura, do município de Campos dos Goytacazes, no dia 20 de janeiro de 2016.

19 Informações verbais fornecidas por Gilvan, pescador da comunidade Ponta Grossa dos Fidalgos, em Campos dos Goytacazes, no dia 15 de maio de 2015. 
Os levantamentos de campo evidenciaram um elevado grau de desconfiança entre os pescadores ao serem sugeridas as possibilidades de ações conjuntas. Mesmo cientes de que essa poderia ser uma saída para a classe pesqueira, conforme relato de um pescador, ao dizer que "[...] com mais união, apareceriam outros mercados e trariam alternativas para não dependerem mais dos atravessadores", logo foi ressaltado o fato de que "[...] há muito pouca organização entre os pescadores" (informações verbais) ${ }^{20}$. Esse motivo dificulta as ações conjuntas para a classe.

A questão da desconfiança dos pescadores artesanais é expandida para as instituições com que eles têm contato. Como exemplo, a Prefeitura de Campos foi apontada como "nada confiável" por 40,6\%; seguida pelo Instituto Estadual do Ambiente (Inea), com 29,1\%; pela Petrobras, com 21,5\%; e pelo Ibama, com 17,7\% das respostas com essa mesma classificação (CENSO PEA-PESCARTE, 2015), conforme é observado em outros trabalhos, como Choueri e Nascimento (2019). Há, portanto, uma espécie de desconfiança generalizada nas instituições públicas, o que leva a uma falta de interesse na busca de órgãos públicos para a solução dos problemas do cotidiano desses trabalhadores e de suas famílias.

\subsection{RESULTADOS DO CENSO DO PROJETO PEA-PESCARTE}

Esta seção busca trazer os resultados encontrados a partir dos questionários aplicados aos pescadores artesanais e às suas famílias nas comunidades pesqueiras de Campos dos Goytacazes. A Tabela 2 indica que mais da metade da produção pesqueira (ou 55,3\%) fica concentrada nas compras realizadas pelos atravessadores, ou seja, na "primeira venda", que é a fonte de receita dos pescadores, o preço de compra não é definido por eles.

Diante desse cenário, as possibilidades de escoamento da produção tendem a ficar cristalizadas. Os “Terceiros (Desconhecidos)" são responsáveis por 23,9\%. Apesar de as pessoas pertencentes a essa categoria pagarem melhor, há um receio entre os pescadores de perderem os "compradores fixos" (os atravessadores), como já apontado nos estudos de Maldonado (1994) e Barbosa (2004), além da questão do próprio perfil da atividade, na qual os pescadores não se predispõem a ficar vendendo o seu pescado. Já os "Comerciantes Locais" representam 19,7\% do pescado. Juntos correspondem a 98,9\% do mercado da "primeira venda" dos pescadores artesanais do município.

${ }_{20}$ Informação verbal fornecida por Zé do Brejo, pescador da comunidade de Tocos, em Campos dos Goytacazes, no dia 24 de abril de 2015. 
Tabela 2 - Com quem é feito o acordo da venda do pescado?

\begin{tabular}{|c|c|c|c|c|c|}
\hline & & 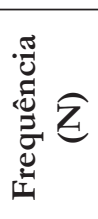 & 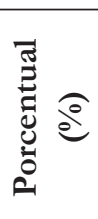 & 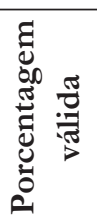 & 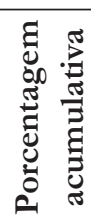 \\
\hline \multirow{5}{*}{ Válido } & Com o atravessador & 104 & 6,3 & 55,3 & 55,3 \\
\hline & Para terceiros (desconhecidos) & 45 & 2,7 & 23,9 & 79,3 \\
\hline & Comerciantes locais & 37 & 2,3 & 19,7 & 98,9 \\
\hline & Com donos de outros barcos & 2 & 0,1 & 1,1 & 100,0 \\
\hline & Total & 188 & 11,4 & 100,0 & - \\
\hline \multirow{4}{*}{ Ausente $^{21}$} & Não se aplica & 1.421 & 86,5 & - & - \\
\hline & Não respondeu & 33 & 2,0 & - & - \\
\hline & Não sabe & 1 & 0,1 & - & - \\
\hline & Total & 1.455 & 88,6 & - & - \\
\hline Total & & 1.643 & 100,0 & - & - \\
\hline
\end{tabular}

Fonte: Censo PEA-Pescarte (2015)

Um dado que vai na contramão das reclamações ouvidas nas reuniões e nos grupos focais foi sobre a preferência para a comercialização do pescado. Como ressaltou Dias Neto (2012), a predileção por realizarem a "primeira venda" do pescado aos atravessadores envolve vários elementos, desde a necessidade financeira, a incapacidade de armazenamento, até questões sociais e familiares. Os dados do censo apontaram que aproximadamente 32,5\% dos pescadores preferem comercializar a sua produção com os atravessadores, fato também observado no estudo realizado por Capellesso e Cazella (2013). Na maioria das vezes, $70,5 \%$ dos pescadores fazem o acordo da venda do pescado com a definição do preço do pescado.

Capellesso e Cazella (2013) destacaram que os atravessadores representam o principal sistema de financiamento dos pescadores. É uma relação entrelaçada com um rol de serviços e suportes oferecidos pelo atravessador que garantem esse vínculo. Em outros casos, a escolha do atravessador ocorre por ordem de parentesco ou grau de amizade. São eles que verificam o preşo do dia com a indústria, fixando uma margem e delimitando o valor a ser pago ao pescador. Mesmo assim, é ressaltado que $50,2 \%$ vendem a sua produção mesmo não estando satisfeitos com preço e com as formas de pagamento oferecidas. Em outras palavras, as relações consolidam economicamente, mas com vínculos

21 Os chamados, no questionário, de "Ausentes", são familiares, como esposas e filhos residentes na casa, mas que não atuavam na pesca, porém a base de dados do Censo PEA-Pescarte considerou todos esses indivíduos. 
sociais, o que implica uma estrutura que define os níveis de acesso e distribuição de riquezas. Tais questões refletem um longo processo histórico de relação de dependência econômica, aliado às características inerentes da atividade da pesca artesanal (CALLOU, 2010; DIEGUES, 1999; RAMALHO, 2012).

A Tabela 3 traz os resultados da pergunta do questionário sobre a renda do pescador; se os seus ganhos são suficientes para suprir todas as suas necessidades. A resposta foi negativa para 80,2\% dos entrevistados. Apenas 19,8\% afirmaram que essa renda seria suficiente. Os dados ressaltam que uma parcela significativa dos pescadores não consegue transcorrer um mês inteiro com os recursos auferidos com o seu ofício.

Tabela 3 - A sua renda é suficiente para suprir todas as necessidades durante um mês?

\begin{tabular}{|c|c|c|c|c|c|}
\hline & & 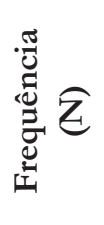 & 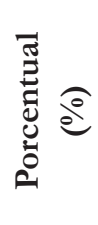 & 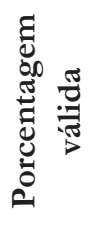 & 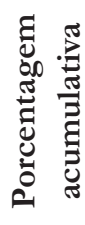 \\
\hline \multirow{3}{*}{ Válido } & Não & 477 & 29 & 80,2 & 80,2 \\
\hline & Sim & 118 & 7,2 & 19,8 & 100,0 \\
\hline & Total & 595 & 36,2 & 100,0 & - \\
\hline \multirow{4}{*}{ Ausente } & Não se aplica & 1.038 & 63,2 & - & - \\
\hline & Não respondeu & 8 & 0,5 & - & - \\
\hline & Não sabe & 2 & 0,1 & - & - \\
\hline & Total & 1.048 & 63,8 & - & - \\
\hline Total & & 1.643 & 100,0 & - & - \\
\hline
\end{tabular}

Fonte: Censo PEA-Pescarte (2015)

As informações coletadas corroboram os achados de Capellesso e Cazella (2011), ao analisarem o cotidiano dos pescadores e pescadoras dos municípios de Garopaba e Imbituba, em Santa Catarina. As alternativas de agregar renda, seja em períodos de baixa na pesca ou durante o Seguro Defeso, partem de fontes extras como: “[...] servente de pedreiro, pedreiro, carpinteiro, guarda de pousadas, caseiro, faxinas, limpeza de terreno, agente de saúde, mecânico, fabricação de redes, manicure; etc.” (CAPELLESSO; CAZELLA, 2011, p. 24). São os chamados "bicos", sem vínculo trabalhista, mas que complementam a renda familiar. Em 80\% dos pescadores ouvidos, a renda tirada do ofício da pesca é insuficiente para a manutenção de suas famílias. 
A baixa expectativa e o horizonte estreito quanto ao futuro da profissão impactam na motivação dos pescadores do município. Como agravante, essa questão tem um efeito que se espalha para os filhos, pois esses estão ainda mais desmotivados em seguir a profissão dos pais. Assim, a possibilidade da descontinuidade na atividade pesqueira, nos moldes praticados por esses pescadores, compromete a intergeracionalidade como um elemento central na manutenção de uma comunidade tradicional. A Tabela 4 deixa evidente esse problema, ao destacar que $81,2 \%$ dos entrevistados não querem que seus filhos sigam essa profissão.

Tabela 4 - Gostaria que seus filhos trabalhassem na pesca?

\begin{tabular}{|c|c|c|c|c|c|}
\hline & & 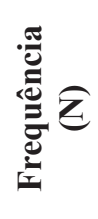 & 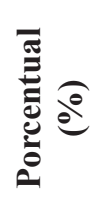 & 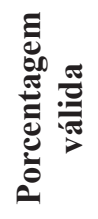 & 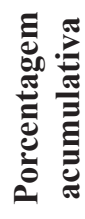 \\
\hline \multirow{3}{*}{ Válido } & Não & 467 & 28,4 & 81,2 & 81,2 \\
\hline & Sim & 108 & 6,6 & 18,8 & 100,0 \\
\hline & Total & 575 & 35,0 & 100,0 & - \\
\hline \multirow{4}{*}{ Ausente } & Não se aplica & 801 & 48,8 & - & - \\
\hline & Não respondeu & 255 & 15,5 & - & - \\
\hline & Não sabe & 12 & 0,7 & - & - \\
\hline & Total & 1.068 & 65,0 & - & - \\
\hline Total & & 1.643 & 100,0 & - & - \\
\hline
\end{tabular}

Fonte: Censo PEA-Pescarte (2015)

Essa questão apareceu nos grupos focais e nas reuniões gerais, em que um dos participantes disse que "[...] ama a pesca, mas não quer que o filho siga o mesmo caminho". Foi dito ainda que "[...] não há vontade de incentivar os filhos a virar pescadores, pois, estaria dando não uma visão de futuro ao filho, mas uma vida muito difícil que vem pela frente" (informação verbal) ${ }^{22}$. Essa fala aponta a preocupação de descontinuidade da pesca artesanal (BARBOSA, 2004).

\section{MERCADOS POTENCIAIS EM CAMPOS DOS GOYTACAZES, RJ}

O levantamento proposto nesta seção é referente ao estudo dos mercados potenciais, ou canais de comercialização, para o escoamento da produção 22 Informação verbal fornecida por Chico Preto, pescador da comunidade de Farol de São Thomé, em Campos dos Goytacazes, no dia 08 de novembro de 2014. 
pesqueira capturada pelos pescadores artesanais do município. Esses canais podem ser percebidos em duas abordagens: os mercados institucionais, alicerçados nas compras públicas, e os circuitos curtos de comercialização entre pescador e consumidor final. Compõem, assim, um "leque" de opções disponíveis com possibilidade real de venda do pescado.

Esse mercado consumidor potencial pressupõe dois grupos: o mercado local de Campos e o das regiões adjacentes. Ao observar as Centrais de Abastecimento (Ceasa) na Figura 1, percebe-se que, em um raio de $200 \mathrm{~km}$ a partir da zona pesqueira de Campos, são encontrados pólos urbanos importantes: à oeste, a região de Juiz de Fora; no sentido norte, a região Sul do estado do Espírito Santo e, entre essas duas regiões, está localizado o Noroeste Fluminense. $\mathrm{Na}$ direção sul, está a capital do estado e sua região metropolitana.

Figura 1 - Localização das CEASA em relação ao município de Campos dos Goytacazes/RJ

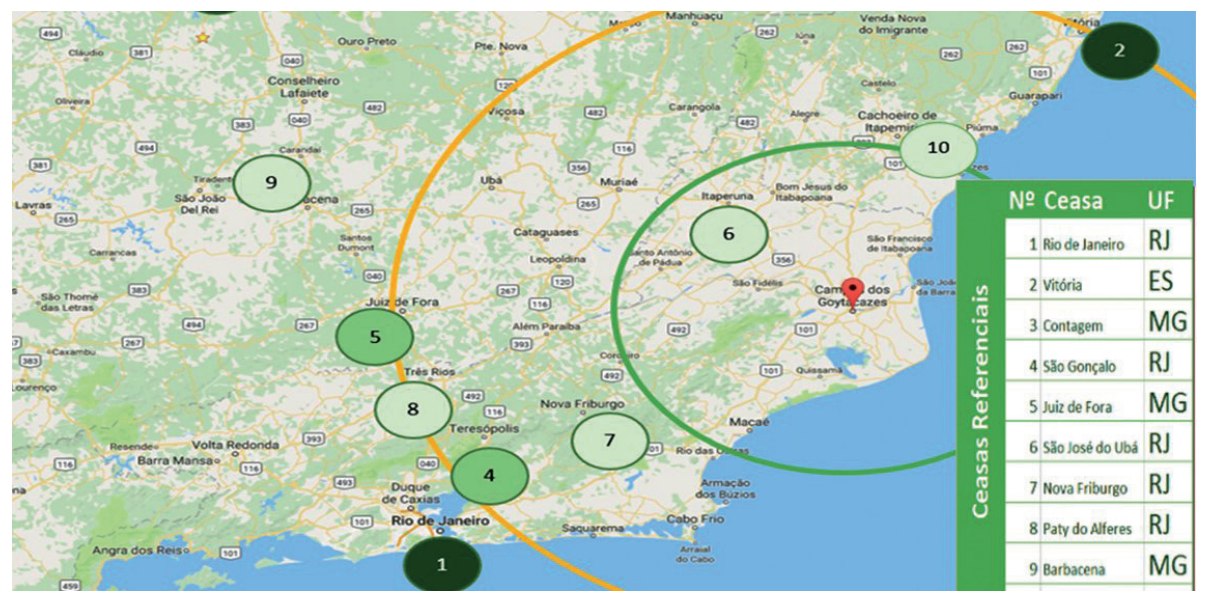

Fonte: Elaborada pelos autores a partir do Google Maps ${ }^{\circledR}, 2020$

Os problemas relacionados à falta de organização e ao planejamento do processo produtivo entre os pescadores impactam na garantia de oferta do pescado para esses canais, na capacidade logística da produção e no poder de barganha de preço. Isso ajuda a pensar o porquê de os pescadores preferirem entregar suas produções aos atravessadores por um preço aquém do real valor de mercado (COSTA, 2019). Desse modo, os pescadores ficam, cada vez mais, distantes dos ideários dos circuitos curtos, em voga nos mercados modernos de abastecimento, que incorporam estabelecimentos como as feiras livres, mercados de pequeno porte e mercados municipais com função varejista (CEPAL, 2014; CUNHA, 2018). 


\subsection{CANAIS PÚBLICOS DE COMERCIALIZAÇÃO NO MUNICÍPIO}

O acesso para a comercialização junto aos canais públicos, como apontado pelo servidor da Secretaria de Agricultura do município, requer questões essenciais como a organização dos pescadores e a obtenção dos selos de qualidade para a comercialização. Além do mais, a organização e o planejamento têm a capacidade de garantir a oferta, primeira condição para as vendas institucionais e, por conseguinte, vincular os pescadores aos programas governamentais, como o Programa de Aquisição de Alimentos (PAA) e o Programa Nacional de Alimentação Escolar (PNAE). Vale ressaltar que há incentivos à aquisição do pescado proveniente dos pescadores artesanais, o que confere um estímulo a esses trabalhadores, contudo quase que a totalidade dos pescadores artesanais não consegue alcançar esses canais de comercialização, e isso se dá por vários motivos, seja a pouca formalização necessária para o comércio com entes públicos, a imprevisibilidade da oferta, dentre outros empecilhos que travam esse canal de comercialização para esses trabalhadores.

Em termos mais objetivos, a principal alternativa de mercado público é o Programa Nacional de Alimentação Escolar (PNAE), que estabelece uma obrigatoriedade do repasse mínimo 30\% dos recursos financeiros transmitidos pelo Fundo Nacional de Desenvolvimento da Educação (FNDE) para a aquisição dos alimentos oriundos da agricultura familiar (ou, como no caso, dos pescadores artesanais), por meio da compra pública que dispensa o processo licitatório.

Para além do consumo potencial via política pública de alimentação escolar, alternativas de escoamento do pescado foram pesquisadas, com base nas cadeias curtas de comercialização, também por meio das compras públicas. Em termos de expectativa, pode-se dizer a possibilidade de vender o pescado (in natura ou processado) para o mercado institucional, formado pelos órgãos governamentais, via modalidade da "compra institucional" pelo PAA. Dessa forma, eles teriam, como mercados potenciais, os órgãos governamentais que fornecem comida para os hospitais, presídios, escolas e restaurantes populares. A Tabela 5 traz as unidades institucionais com potencial para o consumo. 
Tabela 5 - Mercados potenciais públicos de Campos dos Goytacazes (em 2017)

\begin{tabular}{c|c}
\hline Mercados Potenciais Públicos & Número de unidades \\
\hline Escolas & 299 \\
\hline Hospitais & 9 \\
\hline Presídios & 3 \\
\hline Asilos & 2 \\
\hline Restaurante Popular & 1 \\
\hline Restaurante Universitário & 1 \\
\hline Total & 315 \\
\hline
\end{tabular}

Fonte: Elaborada pelos autores, a partir das fontes institucionais

\subsection{CANAIS PRIVADOS DE COMERCIALIZAÇÃO NO MUNICÍPIO}

A construção dos dados para o desenvolvimento desta subseção parte de arranjos potenciais relativos aos canais de comercialização do pescado no município e região. A Tabela 6 traz os resultados (em quantidade e valor) do pescado (independentemente da espécie) comercializado nas 43 Centrais de Abastecimento (CEASA) do país, cuja identificação de origem é Campos dos Goytacazes. Os dados foram coletados a partir do Programa Brasileiro de Modernização do Mercado Hortigranjeiro (Prohort), que é operado pela Companhia Nacional de Abastecimento (Conab), tendo, como objetivo, a integração das bases de dados dos produtos comercializados no mercado atacadista (CUNHA, 2018).

Tabela 6 - Quantidade e Valor do Pescado com origem em Campos dos Goytacazes, RJ, comercializado nas Ceasas brasileiras (2012 a 2016)

\begin{tabular}{c|c|c}
\hline Ano & Quantidade $\mathbf{K g})$ & Valor $(\mathrm{em} \mathrm{R} \mathbf{)}$ \\
\hline 2012 & 2.030 .833 & $14.917 .455,34$ \\
\hline 2013 & 2.662 .869 & $16.093 .163,48$ \\
\hline 2014 & 2.397 .458 & $17.807 .173,90$ \\
\hline 2015 & 1.997 .250 & $11.991 .027,82$ \\
\hline 2016 & 1.775 .671 & $10.538 .047,57$ \\
\hline
\end{tabular}

Fonte: Elaborado pelos autores, a partir de dados do Prohort

Vale ressaltar que os dados acima são subavaliados, levando em conta apenas o que é registrado nas catracas das Ceasas, mas, em valores médios, são 
R \$14,6 milhões por ano, para uma produção, também média, de $2.172 .816 \mathrm{~kg}$. Apenas para o último ano, com registro do Prohort, são mais de R \$10,5 milhões que foram contabilizados nas Ceasas, cuja origem foi identificada como sendo o município de Campos dos Goytacazes.

Os canais de comercialização privados foram coletados por meio de consulta direta à Secretaria Municipal de Campos dos Goytacazes. São, portanto, outras possibilidades de fluxo para a produção pesqueira, configurando como o último segmento a compor o mercado consumidor. $\mathrm{O}$ acesso a esses canais passa pela exigência de inspeção sanitária. Mais uma vez, a organização social e o Selo de Inspeção Municipal (SIM) seriam importantes aliados para atingir esse segmento do mercado consumidor, como é observado na Tabela 7, que traz o levantamento dos pontos de vendas que compõem o mercado privado do município.

Tabela 7 - Mercados potenciais privados de Campos dos Goytacazes (em 2017)

\begin{tabular}{c|c}
\hline Mercados Potenciais Privados & Número de unidades \\
\hline Bares e Restaurantes & 1.356 \\
\hline Hortifrutigranjeiros & 217 \\
\hline Hipermercados e Mercados & 138 \\
\hline Total & 1.711 \\
\hline
\end{tabular}

Fonte: Elaborado pelos autores, a partir das fontes institucionais

Com esses dados coletados, percebe-se a existência de um mix de possíveis canais de comercialização para o pescado produzido no município. No entanto, saber da existência desse potencial mercado consumidor não basta, mas significa um primeiro passo para que esses trabalhadores possam ter expectativas reais de geração de renda. Os entraves são conhecidos (como é o caso das questões burocráticas) para a comercialização da produção pesqueira em escalada com esses mercados. Da mesma forma, as soluções prováveis são também conhecidas, ao menos para a maioria dos pescadores do município, passando pela capacidade de organização e de trabalho coletivo (CAMPOS; TIMÓTEO; ARRUDA, 2018). A reversão, ao menos em parte, desses desarranjos estruturais pode contribuir para que esses pescadores possam alcançar esses mercados "potenciais", que, em tese, têm à sua disposição. São questões que passam, portanto, pela organização social e pela capacidade de gestão, ainda descoladas da maioria dos pescadores artesanais do município. 


\section{CONSIDERAÇÕES FINAIS}

Este artigo almeja, como ponto central, identificar os possíveis canais de comercialização da pesca artesanal das comunidades de Campos dos Goytacazes, por meio das informações oferecidas pelo projeto de mitigação ambiental PEAPescarte. Trata-se de uma análise efetuada, ainda que de forma meramente descritiva, que joga luz sobre o problema da falta de organização social entre os pescadores artesanais.

Os dados apontaram para um mercado da pesca artesanal no município que apresenta um perfil de oligopsônio (MOITA; GOLON, 2014), dada a conjuntura vivida dos pescadores artesanais, que é caracteriza pela existência de um número reduzido de compradores efetivos, nesse caso os atravessadores, que reforçam esse vínculo comercial, como já ressaltado por Maldonado (1994), Duarte (1999), Barbosa (2004) e Costa (2019). Compram mais da metade da produção dos pescadores e definem o preço do pescado. Além disso, consolidam uma relação de dependência que envolve desde os adiantamentos na saída para a pesca até o fornecimento de insumos.

A conquista de "novos mercados" requer organização social entre os pescadores, o que não é uma tarefa simples. A confiança não é o principal atributo entre os pescadores. Isso coloca em xeque as possíveis ações conjuntas e a organização social para a formalização de empreendimento coletivo, por exemplo. A partir dessa iniciativa, permite-se obter escala para viabilizar os selos de inspeção municipal, estadual e federal que são essenciais para o acesso a esses canais de comercialização mais organizados.

Esse estudo, por um lado, apontou uma expressiva capacidade produtiva da pesca artesanal e, por outro, expressou irregularidades na renda pesqueira, que se evidenciam tanto no tempo, por ser uma atividade que trabalha com recursos que não têm controle, como também entre os próprios pescadores e atravessadores.

Por fim, há que se ressaltar a importância relacionada aos aspectos sociais e econômicos decorrentes da atividade da pesca artesanal e de sua relação com um mercado complexo e muito competitivo que, para a sua sobrevivência, requer organização social e que agreguem os seus valores culturais aos produtos. Tais questões condizem com o que se observa para o município de Campos dos Goytacazes, tendo em vista a quantidade de pessoas que estão envolvidas na atividade, identificadas na pesquisa de campo, mas que trazem uma carga de desconfiança, seja nas pessoas, seja nas instituições. É, portanto, um elemento central que reforça a baixa capacidade de organização social entre esses trabalhadores em Campos dos Goytacazes. 


\section{REFERÊNCIAS}

ANDREW, N.; EVANS, L. Approaches and frameworks for management and research in small-scale fisheries in the developing world. The World Fish Center Working Paper 1914, Penang, Malaysia, p. 1-29, 2009.

BARBOSA, S. C. S. Identidade social e dores da alma entre pescadores artesanais em Itaipu, RJ. Revista Ambiente \& Sociedade, Campinas, v. VII, n. 1, p. 107-132, jan./jun. 2004.

BEGOT, L. H.; VIANNA, M. A frota pesqueira costeira do estado do Rio de Janeiro. Rev. Bol. Inst. Pesca, São Paulo, v. 40, n. 1, p. 79-94, 2014.

BRASIL. Lei $\mathbf{n}^{\circ}$ 11. 959, de 29 de junho de 2009. Dispõe sobre a Política Nacional de Desenvolvimento Sustentável da Aquicultura e da Pesca [...]. Brasília, DF: Presidência da República, [2009]. Disponível em: http://www.planalto.gov. br/ccivil_03/_ato2007-2010/2009/lei/111959.htm. Acesso em: 12 jan. 2021.

CALLOU, A. B. F. Povos do mar: herança sociocultural e perspectivas no Brasil. Cienc. Cult., São Paulo, v. 62, n. 3, p. 45-48, 2010.

CAMPOS, M. M.; TIMÓTEO, G. M. A degradação das águas continentais sob a perspectiva dos pescadores artesanais de Bacia de Campos. Brasiliana: Journal for Bazilian Studies, [S. l.], v. 5, p. 225-247, 2017.

CAMPOS, M. M.; TIMÓTEO, G. M.; ARRUDA, A. P. S. N. A dinâmica da pesca artesanal na Bacia de Campos: organização social e práticas em economia solidária entre os pescadores artesanais. Revista Crítica de Ciências Sociais, Coimbra, n. 116, p. 71-102, 2018.

CAPELlessO, A. J.; CAZELLA, A. A. Pesca Artesanal entre Crise Econômica e Problemas Socioambientais: estudo de caso nos municípios de Garopaba e Imbituba (SC). Rev. Ambiente \& Sociedade, Campinas, v. XIV, n. 2, p. 15-33, 2011.

CAPELLESSO, A. J.; CAZELLA, A. A. Os sistemas de financiamento na pesca artesanal: um estudo de caso no Litoral Centro-Sul Catarinense. RESR, Piracicaba, v. 51, n. 2, p. 275-294, 2013.

CENSO PEA-PESCARTE. Projeto de Mitigação Ambiental PETROBRAS/

IBAMA/UENF. Campos dos Goytacazes: PEA-Pescarte, 2015.

CEPAL. Agricultura familiar y circuitos cortos: nuevos esquemas de producción, comercialización y nutrición. Memoria delseminario sobre circuitos cortos.

Naciones Unidas. Seminarios y Conferencias, Santiago, n. 77, p. 1-112, 2014. 
CHOUERI, R. B.; NASCIMENTO, E. P. O papel do licenciamento ambiental federal como ferramenta para gerir conflitos relacionados à biodiversidade aquática e pesca: o caso da UHE Belo Monte. Novos Cadernos NAEA, Belém, v. 22, n. 2, p. 143-163, 2019.

CLAUZET, M.; RAMIRES, M.; BARRELLA, W. Pesca artesanal e conhecimento local de duas populações caiçaras (Enseada do Mar Virado e Barra do Una) no Litoral de São Paulo, Brasil. A Linguagem da Ciência, $[S$. l.], n. 4, p. 1-22, 2005.

LAY, P. M.; OLSON, J. Defining "fishing communities": vulnerability and the Magnuson-Stevens Fishery conservation and management act. Human Ecology Review, [S. l.], v. 15, n. 2, p. 143-160, 2008.

COSTA, K. V. As práticas de comercialização do pescado na pesca artesanal: uma reflexão sobre a subordinação do pescador artesanal ao intermediário no litoral norte fluminense. Revista Agenda Social (UENF), Campos dos Goytacazes, v. 13, n. 1, p. 47-72, 2019.

\section{CUNHA, A. R. A. A. Mercados mayoristas de alimentos en América}

Latina y el Caribe. Santiago: FAO, 2018. 142 p.

DIAS NETO, J. C. Quanto custa ser pescador artesanal ou quanto custa uma política pública? In: ENCONTRO ANUAL DA ANPOCS, 36., 2012, Águas de Lindóia. Anais [...]. Águas de Lindóia: Anpocs, 2012. p. 1-22.

DIEGUES, A. C. Povos e mares: leituras em sócio-antropologia marítima. São Paulo: NUPAUB-USP, 1995.

DIEGUES, A. C. A sócio-antropologia das comunidades de pescadores marítimos no Brasil. Revista Etnográfica, Lisboa, v. 2, p. 361-375, 1999.

DITTY, J.; REZENDE, C. Public participation, artisanal fishers, and the implantation of a coastal megaproject. Rev. Soc. \& Nat., Uberlândia, v. 25, n. 1, p. 51-60, 2013.

DUARTE, L. F. D. As redes do suor: a reprodução social dos trabalhadores da pesca em Jurujuba. Niterói, RJ: Editora da UFF, 1999.

FAO. The State of World Fisheries and Aquaculture 2016. Contributing to food security and nutrition for all. FAO of the United Nations, Rome, 2016. 200 p. LEVKOE, C. Z.; LOWIT'T, K.; NELSON, C. Fish as food: exploring a food sovereignty approach to small-scale fisheries. Marine Policy, [S. l.], v. 85, p. $65-70,2017$. 
MALDONADO, S. C. Mestres \& mares: espaço e indivisão na pesca marítima. 2. ed. São Paulo: Annablume, 1994.

MOITA, R. M.; GOLON, L. A. Oligopsônio dos frigoríficos: uma análise empírica de poder de mercado. RAC, Rio de Janeiro, v. 18, n. 6, p. 772-794, 2014.

PEARSON, D. et al. Local food: understanding consumer motivations in innovative retail formats. British Food Journal, [S. l.], v. 113, n. 7, p. 886-899, 2011.

RAMALHO, C. W. N. Sentimento de corporação, cultura do trabalho e conhecimento patrimonial pesqueiro: expressões socioculturais da pesca artesanal. Rev. de Ciências Sociais, Fortaleza, v. 43, n. 1, p. 8-27, 2012. RIBEIRO, C. G.; INÁCIO JÚNIOR, E. O mercado de compras governamentais brasileiro (2006-2017): mensuração e análise. Rio de Janeiro: IPEA, 2019. (Textos para discussão, 2476).

RODRIGUES, J. A.; GIUDICE, D. S. A pesca marítima artesanal como principal atividade socioeconômica: o caso de Conceição de Vera Cruz, BA. Logepa, Salvador, v. 6, n. 2, p. 155-139, 2011.

SACCO DOS ANJOS, F; NIEDERLE, P. A.; CALDAS, N. V. Pluriatividade e pesca artesanal: o caso da colônia Z-3 em Pelotas, RS. Revista Sociedade em Debate, Pelotas, v. 10, n. 3, p. 9-42, dez. 2004.

SANTOS JÚNIOR, C. A. Sustentabilidade, direito ambiental e meio ambiente: a indústria da pesca em Santa Catarina. Justiça do Direito, Passo Fundo, v. 28, n. 2, p. 334-348, 2014.

SERRA, R.; PATRÃO, C. Impropriedades dos critérios de distribuição dos royalties no Brasil. In: PIQUET, R. (org.). Petróleo, Royalties e Região. Rio de Janeiro: Garamond, 2003. p. 185-216.

SPERS, E. E. Mecanismos da regulação da qualidade e segurança em alimentos. 136 f. Tese (Doutorado em Administração) - Faculdade de Economia e Administração, Universidade de São Paulo, São Paulo, 2003.

VERONESE, M. V.; GUARESCHI, P. Possibilidades solidárias e emancipatórias do trabalho: campo fértil para a prática da Psicologia Social Crítica. Rev. Psicologia \& Sociedade, Porto Alegre, v. 17, n. 2, p. 58-69, 2005. WALDER, A. G. Organizations, social structure, and historical change: towards an historical sociology of organizations. CRSO Working Paper 180, Michigan, p. 1-66, set. 1978 . 
WILLOUGHBY, R.; GORE, T. Ripe for change: ending human suffering in supermarket supply chains, Oxford: Oxfam, 2018. 118 p.

ZAPPES, C. A.; OLIVEIRA, P. C; DI BENEDITTO, A. P. M. Percepção de pescadores do Norte Fluminense sobre a viabilidade da pesca artesanal com a implantação de mega empreendimento portuário. Bol. Inst. Pesca, São Paulo, v. 42, n. 1, p. 73-88, 2016. 